\title{
Vozes Inocentes - Um Olhar Sobre El Salvador (Voces Inocentes)
}

\section{Ignez Gurgel do Amaral *}

Resumo: Esse artigo propõe-se a abordar alguns aspectos significativos do Filme "Vozes Inocentes" de Luis Mandoki editado em 2004, a partir das imagens e sons em movimento. O fio condutor deste trabalho serão as lembranças da personagem principal. Buscaremos, através delas, compreender seu movimento e o que estas lembranças enunciam: a História, a Memória, o Trabalho Infantil, a Chuva. Perceberemos a memória da personagem principal como articuladora entre sentidos e lembranças estas são particulares e desembocam e entrelaçam a memória histórica de El Salvador. O passado da personagem principal (Chava) é evocado na composição das seqüências filmicas, intensificando e despertando suas lembranças, que em movimento moto contínuo constroem o filme.

Palavras-chave: Cinema Latino-Americano, História, Memória, Trabalho Infantil.

Abstract: The purpose of this article is to approach some significant aspects of the Luis Mandoki's movie "Innocent Voices", which was edited in 2004, from images and sounds in movement. The conduct line of this work will be the remembrances of the main character. We seek through them to understand the movie's movement and what those remembrances expose: the History, the Memory, the Infant Labor, the Rain. We will perceive the memory of the main character as articulator among senses, and such remembrances are peculiar, they end and connect the historical memory of El Salvador. The past of the character (Chava) is evoked in the composition of the filmic sequences, intensifying and awakening her remembrances, which build the movie in continuous moto movement.

Keywords: Latin-American Cinema, History, Memory, Infant Labor.

* Doutoranda do Programa de Pós-Graduação em Integração da América Latina da Universidade de São Paulo - PROLAM/ USP. Mestre pela Faculdade de Educação da Universidade de Campinas - UNICAMP. E-mail: ignezgurgel@yahoo.com.br. Recebido em 25/05/06 e aceito em 04/06/06. 
“... a inteligibilidade de um filme acontece nesse misterioso intervalo, entre os cortes e as cenas escolhidas para serem vistas, editadas e montadas, de acordo com a possível e efetiva produção final de um filme, com tudo de artístico e de ideológico do momento de produção desse filme. (...) A interpretação deve partir do caos aparente da imagem, encarar o mistério dos intervalos significantes e valer-se também do caos das teorias, não ter medo do seu aparente conflito." (Almeida, 1999, p. 38-39).

\section{Plano geral sobre El Salvador}

El Salvador é fruto de uma história de luta e resistência. Inicialmente foi incorporado à Capitania Geral da Guatemala, juntamente com alguns outros países da América Central e sua populaçáo - composta por indígenas -, foi dizimada no século XVI. Já no século XIX, a Guatemala foi anexada ao Império Mexicano, essa junção durou poucos anos e suscitou as primeiras tentativas de libertação de El Salvador. Com a derrocada do Império Mexicano, finalmente El Salvador proclamou sua soberania em 1841. Após a libertação, a disputa interna pelo poder deu-se entre conservadores e liberais; estes - representantes da elite - assumem o governo através de uma oligarquia cafeeira, sendo o café a base econômica do país.

O desgaste da oligarquia cafeeira e a crise de 1929 - queda do preço do café - foram responsáveis pelo acirramento das tensóes sociais, levando a população a um levante, reprimido violentamente pelo exército salvadorenho. Durante os anos de repressão, comandada pelo general Maximiliano Hernández Martinez, milhares de civis foram mortos. Em 1944 seu governo é então derrotado por um movimento cívico-militar. Quatro anos mais tarde, surge a figura do tenente coronel Oscar Osório, transformando-se no homem forte do país, apoiado pelo Partido Revolucionário da Unificação Democrática (PRDU). Seu governo se caracterizou pelas políticas voltadas ao desenvolvimento do setor industrial.

Durante a década de 60, apoiado pelo Partido de Conciliação Nacional, o coronel Julio Adalberto Rivera passa a governar o país com forte oposição de partidos de esquerda, principalmente os democratas cristãos que lutavam por uma abertura política. No entanto, os militares permaneceram no comando do país até meados dos anos 80. Em 1979, João Napoleão Duarte assume a 
presidência através de um golpe de estado apoiado por civis e militares. Foi um período de transição que desembocou na forte presença da guerrilha formada pela FMLN (Frente Farabundo Marti de Libertação Nacional). Durante a guerra civil entre guerrilheiros e o exército salvadorenho financiado pelo governo norte-americano e que durou 12 anos -, a economia do país permaneceu estagnada, milhóes foram mortos e outros milhares pediram asilo político. As negociaçóes entre o governo e a FMLN começaram durante o mandato do presidente Duarte e continuaram com o presidente Alfredo Cristiani, eleito em 1989. Ambas as partes aceitaram a mediação da Organizaçáo das Naçóes Unidas (ONU), e depois de um longo tempo de negociaçóes e com o aval da Organização foi firmado um acordo de paz - Tratado de Chapultepec - em janeiro de 1992, embora o final da guerra civil só tenha sido anunciado em dezembro do mesmo ano. A FMLN é atualmente uma referência política da esquerda salvadorenha.

\section{As Vozes Inocentes}

O cinema conta-nos histórias sobre a realidade através das imagens em movimento. Assim, um filme é a construção e criação de fragmentos-parte dessa realidade, escolhidas pelo diretor que transforma espaço, tempo e seres humanos em personagens, cenários, figurinos organizados dentro de uma estrutura fílmica.

Luis Mandoki escolheu a história de Oscar Orlando Torres, que é o roteirista do filme, para mostrar a violência diária pelo qual passavam as pessoas do povoado de Cuscatanzingo, em El Salvador, ao longo da década de 80. A guerra civil era alimentada pelo conflito agrário que acabou se transformando num violento confronto entre o exército salvadorenho e os camponeses organizados no movimento guerrilheiro FMLN (Frente Farabundo Marti de Libertação Nacional) ${ }^{1}$. Grande parte dos combatentes, porém, era oriundo do recrutamento forçado de crianças. No mundo todo, mais de 300 mil crianças têm sido recrutadas em exércitos. Em El Salvador, os meninos ao completar 12 anos de idade eram levados para servir ao exército e defender a pátria - lema este lembrado constantemente

\footnotetext{
${ }^{1}$ Herói martirizado da esquerda salvadorenha, um organizador comunista da insurreição indígena de 1932. Além disso, Martí lutara com Sandino na Nicarágua contra as forças norte-americanas. Na década de 1980, A FSLN (Frente Sandinista de Libertação Nacional) procurou retribuir o favor ajudando a FMLN (Frente Farabundo Marti de Libertação Nacional) contra o exército salvadorenho apoiado pelos Estados Unidos.
} 
durante o recrutamento. Retirados da escola, muitos sem conter o choro, encaminhavam-se diretamente para os campos de treinamento. A grande maioria tinha até menos de 12 anos mas já aprendiam desde cedo, sob o jugo dos olhares ácidos dos soldados, a levar as armas em punho, exercendo o poder em relação àqueles que morriam por suas balas, pelos seus gestos treinados, mecânicos. Eram crianças sendo transformadas em soldados, em pequenos "adultos". Oscar Orlando Torres (Chava) dedica o filme aos seus amigos que foram mortos, ainda crianças, dos quais muitos deles executados pelo próprio exército salvadorenho.

Segundo a Organização Internacional do Trabalho (OIT):

Trabalho infantil é um conceito mais restrito do que "crianças economicamente ativas", excluindo todas as crianças com 12 ou mais anos que trabalham apenas algumas horas por semana em trabalhos leves autorizados e aquelas com 15 ou mais anos cujo trabalho não é classificado como "perigoso". O conceito de "trabalho infantil" baseiase na Convenção da Idade Mínima da OIT, de 1973 (N. ${ }^{\circ}$ 138)², que constitui a mais completa e oficial definição internacional sobre a idade mínima de admissão ao emprego ou ao trabalho, indicando uma atividade econômica. (OIT, 2006, p. 12)

Não era apenas o exército quem absorvia crianças para a guerra. A guerrilha, composta em sua grande maioria por camponeses, era um pólo de atração para as crianças que se identificavam com as causas de seus familiares. Durante a guerra civil, os EUA enviaram mais de 1 milhão de dólares em ajuda militar, além de militares para aprimorar o treinamento do exército salvadorenho e de suas crianças. A Guerra Civil durou 12 anos, morreram mais de 75 mil pessoas.

O número de crianças envolvidas em conflitos armados tem aumentado de forma significativa na última década, sendo estimando em cerca de 300.000. Muito embora, muitas sejam mais velhas, com 15 anos de idade

\footnotetext{
2 "Art. 1" - Todo país-membro, no qual vigore esta Convenção, compromete-se a seguir uma política nacional que assegure a efetiva abolição do trabalho infantil e eleve, progressivamente, a idade mínima de admissão a emprego ou trabalho em um nível adequado ao pleno desenvolvimento fisico e mental do jovem." (Resoluções da OIT, 1973).
} 
ou mais, tem-se observado uma tendência dramática para o recrutamento de crianças mais novas. O rapto de crianças durante conflitos armados é um problema grave, conduzindo à escravidáo sexual ou ao trabalho forçado (...). É por estas razóes que a Convenção N. 182 define "recrutamento forçado ou obrigatório" de crianças com menos de 18 anos de idade, com vista à sua utilização em conflitos armados, como uma das piores formas de trabalho infantil. (OIT, 2006. p. 65)

De volta ao cenário, vemos tiros furarem as paredes dos casebres, a pobreza ofuscando o lugar, a chuva caindo torrencial. Dentro da casa, Ricardo, o irmáo mais novo de Chava, chora de pavor. Os tiros não param e destroem objetos. As balas zumbem desesperadas em busca da destruição. Chava se disfarça de palhaço, pinta o nariz, faz gestos engraçados para distrair os irmãos, para ludibriar o tempo que não cessa de matar, projéteis perdidos encontram corpos de crianças, que morrem nos braços das mães. Ele é o homem da casa, desde que seu pai os abandonou e foi embora para os EUA. É ele que protege, que trabalha para garantir a sobrevivência da família. A madrugada traz de volta ao lar sua mãe que, ao chegar, encontra-os dormindo debaixo da cama. Seu medo de perdê-los se transformara em rotina.

\section{Percepções sobre a chuva}

Vozes Inocentes é um filme que transita entre o drama, o romance juvenil e a Guerra Civil. A história de Chava é uma montagem de sua memória, sendo que esta apresenta uma narrativa no qual o espaço fílmico está repleto de alternâncias. $\mathrm{Na}$ abertura e encerramento do filme, as cenas mais lentas demonstram a limitação sócio-econômica e cultural da própria história da personagem principal. A lentidão das imagens mostra que o ponto de partida e chegada é o mesmo: a dor, a morte, o exílio... expondo as dores, o cansaço e a angústia do pequeno Chava e de seus amigos, prolongando o tempo e procrastinando um acontecimento que virá: a morte.

A chuva é intensa. Chove, chove quase todo o filme, é como se a grande torrente de água quisesse levar a dor e o desespero dos habitantes do pequeno povoado, como se quisesse lavar o sangue dos mortos estirados nas vielas, junto ao rio, nas pequenas ruas, como se a chuva fosse capaz de carregar as adversidades, o perigo iminente, no qual viviam aquelas crianças, de 
fazer brotar da terra molhada o esquecimento. O diretor utiliza a fusão, na superposiçáo das cenas - quando uma apaga a outra aparece - num entrelaçamento contínuo, mantendo a fluidez e a suavidade da seqüência.

Nos diz Wencesláo:

Parto do princípio de que as chuvas que vemos no cinema não são chuvas oriundas da Natureza, mas da Cultura. As chuvas que assistimos no cinema não molham. O lugar de onde brotam as águas de cima é a Memória e não as nuvens. Talvez, por isto, não se faz necessário vermos nuvens que anunciariam a chuva que virá. (...) São todos signos visuais e sonoros que não seguem em seqüência de aparição as leis do ciclo da água na Natureza, mas os sentidos e significados impostos pelo fio narrativo e estético da história filmada. (...) Ao cruzar a linha demarcatória entre Cultura e Natureza, as chuvas dos filmes nos reinserem nesta última sem contudo nos retirar da primeira. No cinema, pela sua real verossimilhança, as chuvas são materiais - produto da Natureza- e simbólicas - produto da Cultura - ao mesmo tempo. (OLIVEIRA JUNIOR, 1999, p. 14-15)

Uma voz introduz o espectador nesse ambiente ainda estranho e vai unindo aos poucos imagem e som. "Estou com muita sede, me doem os pés, tenho pedras no sapato."

Ao longe se vêem os soldados escoltando os meninos. As botas dos soldados afundam na lama. A chuva cai e desce ladeira abaixo. A paisagem é aberta, escura, sombria, rostos impassíveis passam por alguns casebres e as mães tomam seus filhos nos braços, sentem medo. A chuva castigava os corpos dos meninos que andam ao encontro da morte. Os trovóes misturamse à música melancólica...

A chuva traz o primeiro amor de Chava, Cristina Maria. Amor de criança, de escola, de brincadeiras, de sorrisos, do primeiro beijo, amor leve como os balóes que eles soltavam quando subiam nas árvores, corriam na chuva; quando ele e os amigos cantavam na porta de sua casa. Amor que os soldados interromperam e que a chuva abundante carregou. Amor carregado de sofrimento, ajuntado com o rio que levou nas suas vagas o que restou de Cristina Maria. Via-se seu rosto em detalhes. As lágrimas desciam em longas torrentes de tristeza de menino e Chava foi embora com sua dor em aberto. 


\section{Entre as sendas da memória}

Claridade, sol, luz. A chuva dá uma trégua. Chava corre e sorri. É como se perseguisse a câmera. Entra em casa distraído e vê sobre a mesa um bolo repleto de velas. Com sua chegada, todos saem de seus esconderijos e cantam parabéns. Em meio à cantiga ele corre em desespero, pois se lembra que acaba de completar doze anos e não há mais como fugir do recrutamento. Ele chora e Cristina Maria o abraça, entregando-lhe um presente. Ele sorri e logo o medo se encontra no lugar obscuro e mal iluminado, que é o esquecimento.

A noite escura é composta por tiros, sombras se movimentam entre os casebres entrincheirados. Guerrilheiros de lenços vermelhos cobrindo-lhes o rosto atiram com sofreguidão em direção à massa verde de soldados que respondem veementes aquele diálogo de fogo. Dentro da casa de Chava, seu tio Beto - que é guerrilheiro -, atira pela janela, defendendo seus ideais e sua família. Em meio à chuva de tiros, ouvem-se gritos na casa ao lado. Chava e seu tio correm e, ao chegarem lá, vem uma menina agonizante nos braços da mãe. Uma bala perdida acertara seu alvo. Eles retornam para casa e seu tio canta e toca para ele uma canção que jamais esqueceria: "Casas de Cartón". A música guardava suas lembranças, compunha sua memória. "¿Qué es la memoria? La memoria es un glorioso y admirable don de la naturaleza por el que recordamos las cosas pasadas, abrazamos las cosas presentes y contemplamos las cosas futuras por su parecido con las pasadas." (YATES, 1974, p. 77)

$\mathrm{O}$ toque de recolher soa e todos correm para casa. É a anunciação, o pré-núncio de algo que já sentiam, que já sabiam: os soldados, os tanques, as armas, os uniformes, a violência contra as mulheres, os furtos. A guerra trazia o poder, o poder que circulava entre a população, representado pelos guerrilheiros e as forças armadas, em um jogo de forças. A Igreja e muitas famílias colaboravam com os guerrilheiros pois acreditavam na resistência, na luta pela terra e na liberdade. Tinham seus códigos próprios, suas condutas e formas de se ajudarem mutuamente, entretanto a punição vinha através da morte de seus filhos e do recrutamento que era inevitável. "A forma de conduzir a guerra é portanto, em detalhe, a imagem exata do que ocorre no plano geral: pretende-se ser a maior massa de vivos. Do lado adversário deve ficar o monte maior de mortos. (...) o motivo de fundo essencial, poderíamos até dizer, o motivo básico mais profundo das guerras. Em vez de mortos 
também se podem fazer escravos, principalmente mulheres e crianças..." (CANETTI, 1983, p. 72)

Os soldados invadiam as escolas, as casas, as ruas, inclusive a Igreja onde o padre por compactuar com os guerrilheiros é capturado. A cidade é uma trincheira na qual a população vive no fogo cruzado entre forças armadas e guerrilha. $\mathrm{O}$ poder circula de mão em mão, passando por todas, dos soldados que puniam,- sem nem saber as causas de seus atos,- aos guerrilheiros que respondiam as puniçóes com outra forma de poder, a resistência.

Como fala-nos Foucault:

(...) o poder não se aplica aos indivíduos, passa por eles. Não se trata de conceber o indivíduo de núcleo elementar, átomo primitivo, matéria múltipla e inerte que o poder golpearia e sobre o qual se aplicaria, submetendo os indivíduos ou estraçalhando-os. Efetivamente, aquilo que se faz com que um corpo, gestos, discursos e desejos sejam identificados e constituídos é um dos primeiros efeitos do poder. (...) O indivíduo é um efeito do poder e simultaneamente, ou pelo próprio fato de ser um efeito, é seu centro de transmissão. O poder passa através do indivíduo que ele constituiu. (FOUCAULT, 1981, p. 183-184)

Fogo. As casas ardem aos pedaços. O que sobrou da população deixa em bando a cidade, destruída em ruínas; atravessam com seus parcos pertences uma grande ponte. A mãe de Chava chora e sai em busca do filho; Chava escapa da execução e encontra sua mãe nos escombros do que restou de sua casa. Ele parte para os EUA para fugir do recrutamento, sua mãe vende seu único objeto de valor, a máquina de costura, fonte de trabalho e renda. Chava parte com outras crianças e famílias que também fogem da guerra e promete voltar quando seu irmão completar 12 anos para buscá-lo. E assim o faz.

O filme permite ao espectador relacionar-se com o tempo das imagens, com sua plasticidade e desta forma senti-las e dialogar com elas. A história dramática, porém não apelativa, possui um elenco homogêneo no tocante às interpretaçóes. Todos demonstram boa atuação. As imagens são bonitas e vivas e a música encaixa-se perfeitamente a elas. O filme se encerra abrindonos um caminho de retorno ao passado histórico, político e social através das lembranças-memórias de Oscar Orlando Torres, de El Salvador, da América 
Latina e de suas crianças lançadas ao trabalho infantil.

Olhar um quadro, uma escultura, uma fotografia, um filme, uma imagem abre-nos a possibilidade de relação, de comunicação, de narrativa, com o que estamos vendo, com o que ela nos faz sentir, produzir, criar. Saímos do limite físico do que estamos olhando, do imutável para o inesgotável mundo da imaginação podendo, assim, dialogar com pinturas, esculturas, fotografias, imagens, filmes de outros tempos, de outras culturas, que nos falam através de uma linguagem de representaçóes, formas, estilos, feitios, cores, linhas... A imagem é um vasto mundo que se abre. 


\section{Referências Bibliográficas}

ALMEIDA, Milton José. Cinema, arte da memória. Campinas: Editora Autores Associados, 1999.

CANNETI, Elias. Massa e poder. São Paulo: Editora Universidade de Brasília/ Melhoramentos, 1983.

FOUCAULT, Michel. Microfísica do poder. Rio de Janeiro: Ediçôes Grall, 1981.

OIT - ORGANIZAÇÃO INTERNACIONAL DO TRABALHO. Relatório Global no quadro do Seguimento da Declaração da OIT sobre os Princípios e Direitos Fundamentais no Trabalho. Conferência Internacional Trabalho, 95a Sessão, 2006.

OLIVEIRA JÚNIOR, Wenceslao Machado de. Chuva de cinema - natureza e culturas urbanas. Campinas, 1999. Tese (Doutorado) - Faculdade de Educação, Universidade Estadual de Campinas - UNICAMP.

YATES, Frances A. El arte de la memória. Salamanca-Madrid: Ediçôes Taurus, 1974. 